\title{
Pembelajaran Memorisasi dalam Ulangan 6:6-9
}

\author{
I Putu Ayub Darmawan \\ Sekolah Tinggi Teologi Simpson, Ungaran, Jawa Tengah, Indonesia \\ putuayub.simpson@gmail.com
}

\begin{tabular}{l} 
Article History \\
Received: \\
18 Mei 2019 \\
Revised: \\
none \\
Published: \\
31 Mei 2019 \\
\hline \\
Keywords \\
(Kata kunci): \\
Deutronomy; \\
education; learning; \\
memorization; \\
memorisasi; \\
pembelajaran; \\
pendidikan; Ulangan
\end{tabular}

\section{Abstrak}

Alkitab dalam Ulangan 6:6-9 memberikan perintah untuk melaksanakan pendidikan anak. Teks Ulangan 6:6-9 umumnya dipahami sebatas sebagai mandat pendidikan dalam keluarga, tetapi penulis memandang jika teks Ulangan 6:6-9 juga menunjukkan sebuah model pembelajaran. Untuk itu penulis melakukan analisis terhadap teks Ulangan 6:6-9. Dari analisis terhadap teks tersebut tampak jika terdapat proses pembelajaran memorisasi. Proses pembelajaran memorisasi dilakukan dengan menyampaikan pengajaran secara berulang dan disertai dengan media yang tersedia di lingkungan keluarga. Pembelajaran ini secara teoritis membantu untuk meningkatkan pemahaman sebab terjadi proses perekaman, penyimpanan, dan pemanggilan yang lebih efektif dan memungkinkan terjadinya pendalaman terhadap makna pada suatu informasi.

\section{Pendahuluan}

Dalam Perjanjian Lama terdapat beberapa teks yang berkaitan dengan pendidikan baik pendidikan anak maupun pendidikan keluarga. Beberapa kitab Perjanjian Lama yang membahas pendidikan adalah kitab Keluaran 12:24-27, Ulangan 6:6-9, dan Mazmur 78:5-6. ${ }^{1}$ Ulangan 6:6-9 merupakan salah satu teks dalam Perjanjian Lama yang umumnya diangkat sebagai landasan alkitabiah untuk pendidikan anak maupun pendidikan dalam keluarga. Dalam kajian yang dilakukan oleh Heryanto, Ulangan 6:6-9 cenderung hanya dipahami sebagai tanggungjawab orang tua untuk mengajar anak-

\footnotetext{
${ }^{1}$ Maria Lidya Wenas and I Putu Ayub Darmawan, "Signifikansi Pendidikan Anak Dalam Perspektif Alkitab," Evangelikal: Jurnal Teologi Injili dan Pembinaan Warga Jemaat 1, no. 2 (2017), http://journal.sttsimpson.ac.id/index.php/EJTI.
} 
anaknya. $^{2}$ Demikian pula dalam tulisan Tety dan Wiraatmadja, teks Ulangan 6:6-9 dipahami sebagai fondasi alkitabiah untuk pendidikan anak, hanya terdapat sebuah proses melaksanakan pendidikan tersebut. ${ }^{3}$ Demikian juga dalam penelitian Wenas dan Darmawan, aktivitas dalam teks Ulangan 6:6-9 merupakan sebuah aktivitas pembelajaran yang dilakukan secara intensif dan berkelanjutan. ${ }^{4}$ Beberapa penelitian tersebut tampak terhenti hanya pada menjadikannya sebagai fondasi alkitabiah untuk pendidikan anak.

Rantesalu dalam penelitiannya justru sedikit berbeda dengan penelitian lainnya. Menurut Rantesalu, Ulangan 6:7-9 justru memberikan penekanan pada kemampuan yang harus dimiliki oleh seorang guru dalam mengajarkan nilai-nilai iman. ${ }^{5}$ Kegiatan pembelajaran merupakan sebuah usaha untuk menyampaikan pengetahuan, pembentukan konsep, dan penanaman nilai-nilai moral. Untuk melaksanakan kegiatan tersebut seorang pengajar akan merancang kegiatan pembelajaran mulai dari pembagian materi, penentuan metode dan pemilihan media, serta pengalokasian waktu. Dari rangkaian kegiatan tersebut tampak jika penetuan metode dan pemilihan media memegang peranan penting. Nurseto menjelaskan bahwa untuk menciptakan proses pembelajaran yang efektif dan berkualitas diperlukan pemilihan model pembelajaran yang tepat. Oleh sebab itu seorang pengajar perlu memilih dengan cermat model pembelajaran yang akan digunakan. ${ }^{6}$

Dalam analisis awal penulis teks Ulangan 6:6-9 tidak hanya berbicara tentang pendidikan dalam keluarga tetapi ada kegiatan pembelajaran. Proses pembelajaran dengan model mengulang identik dengan pembelajaran yang menekankan pada ingatan dan pemahaman. Dalam taksonomi pembelajaran Bloom revisi, mengingat dan memahami adalah tujuan pembelajaran yang perlu dicapai pada tahap awal. Oleh sebab itu perlu sebuah pendalaman tentang proses pembelajaran dalam Ulangan 6:6-9 sehingga dapat memberi kontribusi bagi pengembangan pembelajaran.

Rumusan masalah dalam penelitian ini adalah bagaimana pembelajaran memorisasi yang terdapat dalam Ulangan 6:6-9? Kemudian tujuan penelitian ini adalah untuk memaparkan tetang pembelajaran memorisasi yang terdapat dalam Ulangan 6:6-9. Penelitian ini diharapkan dapat memberikan manfaat teoritis bagi pengembangan pendidikan Kristen khususnya pendidikan anak.

\footnotetext{
${ }^{2}$ Heryanto Heryanto, "Signifikansi Nilai Budaya Kristen Dalam Kepemimpinan Guru di Lingkungan Sekolah Kristen,” GENERASI KAMPUS 11, no. 1 (November 2018).

${ }^{3}$ Tety Tety and Soeparwata Wiraatmadja, "Prinsip-Prinsip Filsafat Pendidikan Kristen," Evangelikal: Jurnal Teologi Injili dan Pembinaan Warga Jemaat 1, no. 1 (January 2017): 55-60.

${ }^{4}$ Maria Lidya Wenas and Darmawan, "Signifikansi Pendidikan Anak Dalam Perspektif Alkitab."

${ }^{5}$ Syani Bombongan Rantesalu, "Kompetensi Pedagogik Menurut Analisis Ulangan 6:7-9 dengan Pendekatan Hermeneutik Schleiermacher," BIA': Jurnal Teologi dan Pendidikan Kristen Kontekstual 1, no. 2 (December 2018): 153-163.

${ }^{6}$ Tejo Nurseto, "Membuat Media Pembelajaran yang Menarik," Jurnal Ekonomi dan Pendidikan 8, no. 1 (2011): 19-35.
} 


\section{Metode}

Pendekatan penelitian yang digunakan dalam penelitian ini adalah hermeneutik Alkitab atas teks Ulangan 6:6-9, yang dalam Alkitab Terjemahan Baru tertulis:

Apa yang kuperintahkan kepadamu pada hari ini haruslah engkau perhatikan, haruslah engkau mengajarkannya berulang-ulang kepada anak-anakmu dan membicarakannya apabila engkau duduk di rumahmu, apabila engkau sedang dalam perjalanan, apabila engkau berbaring dan apabila engkau bangun. Haruslah juga engkau mengikatkannya sebagai tanda pada tanganmu dan haruslah itu menjadi lambang di dahimu, dan haruslah engkau menuliskannya pada tiang pintu rumahmu dan pada pintu gerbangmu.

Penulis melakukan analisis terhadap teks Ulangan 6:6-9, kemudian menyajikan sebuah tafsiran yang dielaborasi dengan berbagai sumber relevan.

\section{Garis Besar Ulangan 6:6-9}

Garis besar teks Ulangan 6:6-9 adalah sebagai berikut:

Perintah Allah (ayat 6)

Proses pembelajaran (ayat 7)

Melakukan pengulangan

Membicarakan dalam berbagai situasi

Media pendukung (ayat 8-9)

\section{Tafsiran}

Dari analisis terhadap Ulangan 6:6-9 tampak jika orang Israel mengajar anakanaknya dengan model pembelajaran memorisasi. Dalam teks Ulangan 6:7 tampak jika terdapat perintah agar mengajar perintah Tuhan kepada anak-anak secara berulangulang. Dalam bahasa Ibrani "mengajarkannya berulang-ulang" dituliskan dalam kata שנן (shanan) yang dapat diartikan sebagai ajarkan dengan rajin. Menurut Calvin kata שנן yang digunakan oleh Musa dalam ayat tersebut berarti "untuk mengasah."7 Mengajarkan dengan rajin tampak dari kegiatan pembelajaran yang dilakukan saat duduk di rumah, saat sedang perjalanan, berbaring dan saat bangun. Itu artinya proses pembelajaran dilakukan setiap waktu saat orang tua bersama anak-anaknya, sehingga orang tua dapat terus mengasah ingatan anak-anaknya. Proses pembelajaran yang menekankan pada ingatan tersebut dilaksanakan dengan memanfaatkan berbagai media seperti mengikatkan tanda pada tangan dan membuat lambang di dahi kemudian menuliskan pada tiang pintu rumah serta pada pintu gerbang (Ul. 6:8-9). Tindakan tersebut menurut Henry dilakukan dengan penuh hormat dan kesungguhan agar bangsa Israel menanamkan perintah Tuhan di dalam hati mereka, sehingga dapat menimbulkan kebaikan pada anak-anak mereka. ${ }^{8}$ Refleksi praktis dari teks Ulangan 6:6-9 diungkapkan oleh Spurgeon, bahwa cara yang diungkapkan dalam teks tersebut

${ }^{7}$ John Calvin, “Deuteronomy 6 Commentary - John Calvin's Commentaries on the Bible," StudyLight.org.

${ }^{8}$ Matthew Henry, "Deuteronomy 6 Commentary - Matthew Henry's Complete Commentary on the Bible," StudyLight.org. 
tentunya akan mendorong orang Kristen memiliki lebih banyak waktu untuk belajar dan berbicara tentang Firman Tuhan, baik saat duduk maupun saat berjalan. ${ }^{9}$

Penggunaan media tiang pintu rumah dan pintu gerbang untuk mengajarkan Taurat Tuhan terkait dengan kebiasaan arsitektur pada masa Musa. Wycliffe menjelaskan jika pelaksaannya dilakukan dengan memasang hiasan-hiasan di tiang pintu dan pintu gerbang. ${ }^{10}$ Teks dalam Matius 23:5 menunjukkan jika kebiasaan untuk memasang hiasan di tiang pintu dan pintu gerbang terus dilakukan atau menjadi semacam tradisi yang terus dijaga. Sementara Rantesalu mengungkapkan bahwa perintah untuk mengikatkan pada tangan dan dahi dipahami sebagai sebuah simbol yang kemudian dilakukan secara harafiah. Secara harafiah, media tersebut dilaksanakan dengan membuah kota-kotak kecil yang terbuat dari kulit dan dibagi dalam empat ruang yang isinya ayat-ayat Keluaran 13:1-10, Keluaran 13:11-16, Ulangan 6:4-9; 11:13-21. ${ }^{11}$

\section{Pembahasan}

\section{Pembelajaran dengan Pengulangan}

Dari tafsiran di atas maka tampak jika pembelajaran memorisasi dilakukan dengan mengajarkan dengan pengulangan. Arianto menyatakan jika kemampuan untuk menangkap dan mengingat dipengaruhi oleh kemampuan untuk menyimak. ${ }^{12}$ Karena pembelajaran dilakukan dengan terus mengulang maka secara kuantitas terjadi peluang untuk menyimak apa yang diajarkan dalam jumlah yang lebih sering. Kemudian dengan pengulangan yang dilakukan secara terus menerus diberbagai situasi maka intensitas menerima pengajaran menjadi lebih sering kemudian memungkinkan terjadi situasi belajar yang baik.

Windariyah menjelaskan jika kata menghafal disebut sebagai memori, yang bagi manusia menjadi bagian dalam proses mengolah informasi mulai dari perekaman, penyimpanan, dan pemanggilan. ${ }^{13}$ Apabila terjadi pengulangan maka akan terjadi proses perekaman secara berulang-ulang, itu artinya informasi yang sama akan direkam dalam jumlah lebih banyak lalu tersimpan dalam jumlah yang lebih banyak juga. Dengan demikian proses pemanggilannya akan menjadi lebih mudah. Itu berarti bahwa proses pembelajaran memorisasi dalam Ulangan 6:6-9 memungkinkan anak-anak untuk lebih banyak merekam, kemudian menyimpan informasi dan terjadi penguatan pada informasi yang disimpan. Proses yang terjadi secara terus menerus tidak hanya akan menghasilkan informasi yang tersimpan lama, tetapi memungkinkan terjadi pemahaman yang lebih baik pada informasi yang telah diterima.

${ }^{9}$ C. Spurgeon, "Deuteronomy 6 Commentary - Spurgeon's Verse Expositions of the Bible," StudyLight.org.

${ }^{10}$ Charles F. Pfeiffer and Everett F. Harrison, Tafsiran Alkitab Wycliffe Vol. 1 (Malang: Gandum Mas, 1962).

${ }^{11}$ Rantesalu, "Kompetensi Pedagogik Menurut Analisis Ulangan 6."

${ }^{12}$ Arianto Arianto, "Model Pembelajaran Terpadu Untuk Meningkatkan Keterampilan Menyimak Dan Berbicara," Al-Izzah: Jurnal Hasil-Hasil Penelitian 13, no. 1 (May 2018): 48-62.

${ }^{13}$ Devi Suci Windariyah, "Kebertahanan Metode Hafalan Dalam Pembelajaran Bahasa Arab," TA 'LIM : Jurnal Studi Pendidikan Islam 1, no. 2 (July 2018): 89-104. 
Ibrahim et al, memaparkan bahwa dalam memorisasi ada dua proses memorisasi yaitu proses memorisasi kata-kata verbal maupun nor verbal dan proses memorisasi makna. Proses memorisasi tersebut memampukan seseorang untuk menemukan maupun menciptakan pengetahuan. Dengan demikian ada proses untuk meningkatkan pemahaman pada sebuah informasi. ${ }^{14}$ Bila mengacu pendapat Ibrahim et al dan membandingkannya dengan hasil analisis terhadap Ulangan 6:6-9 maka pembelajaran yang terjadi adalah pembelajaran yang berkaitan dengan memorisasi kata-kata verbal, memorisasi non verbal dan memorisasi makna. Memorisasi kata-kata verbal dan memorisasi makna terjadi melalui proses penyampaian pengajaran secara berulang serta membicarakannya (דבר dabar) dalam berbagai situasi.

Dalam taksonomi pembelajaran Bloom revisi pemahaman terjadi karena adanya proses kognitif yaitu adanya transfer informasi yang terjadi dengan jelas dan berkelanjutan. ${ }^{15}$ Krathwohl yang merevisi taksonomi Bloom menjelaskan bahwa seseorang dapat dikatakan memahami jika orang tersebut mampu mengkonstruksi pesan yang telah diterima dalam berbagai bentuk seperti bentuk lisan, tulisan dan grafis. ${ }^{16}$ Ketika penulis mencermati proses pembelajaran yang terjadi secara terus menerus dari generasi ke generasi maka tampak jika ada kemampuan memahami perintah Tuhan dalam Ulangan 6:5. Dalam Ulangan 6:5 dituliskan "Kasihilah TUHAN, Allahmu, dengan segenap hatimu dan dengan segenap jiwamu dan dengan segenap kekuatanmu." Lalu dalam tradisi orang Yahudi tindakan dalam ibadah menunjukkan sebuah bentuk memahami perintah tersebut, walau kemudian perintah tersebut cenderung hanya dipahami sebagai sebuah tradisi tanpa sebuah pendalaman padan maknanya. Kebiasaan yang tergambar dalam Matius 23:5-7 menunjukkan jika perintah dalam Ulangan 6:5 kurang dipahami dengan baik. Tetapi secara keseluruhan proses pembelajaran tersebut telah menanamkan informasi dalam jangka panjang.

\section{Menggunakan Media Pendukung}

Perintah agar mengikatkan taurat Tuhan menjadi sebuah tanda pada tangan kemudian menjadi lambang pada dahi, lalu menuliskannya pada tiang pintu rumah dan pada pintu gerbang (Ul. 6:8-9) menunjukkan jika proses pembelajaran tidak hanya dilakukan secara verbal melainkan juga secara non verbal. Mengacu pada pendapat Rantesalu, perintah untuk mengikatkan pada tangan dan dahi kemudian dilaksanakan dengan membuat kota-kotak kecil yang terbuat dari kulit. ${ }^{17}$

\footnotetext{
${ }^{14}$ Teguh Ibrahim et al., "Profil Karakter Guru Pembelajar: Sebuah Kerangka Konseptual," NATURALISTIC: Jurnal Kajian Penelitian Pendidikan dan Pembelajaran 2, no. 1 (October 2017): 8-22.

${ }^{15}$ I. Putu Ayub Darmawan and Edy Sujoko, "Revisi Taksonomi Pembelajaran Benyamin S. Bloom," Satya Widya 29, no. 1 (June 2013): 30-39.

${ }^{16}$ Lorin W. Anderson and David R. Krathwohl, Kerangka Landasan Untuk Pembelajaran, Pengajaran Dan Asesmen: Revisi Taksonomi Pendidikan Bloom (Yogyakarta: Pustaka Pelajar, 2010); David R. Krathwohl, “A Revision of Bloom's Taxonomy: An Overview," Theory Into Practice 41, no. 4 (November 2002): 212-218.

${ }^{17}$ Syani Bombongan Rantesalu, "Kompetensi Pedagogik Menurut Analisis Ulangan 6:7-9 dengan Pendekatan Hermeneutik Schleiermacher," BIA': Jurnal Teologi dan Pendidikan Kristen Kontekstual 1, no. 2 (December 2018): 153-163.
} 
Merujuk pada pendapat Ibrahim et al yang menjelaskan bahwa proses memorisasi juga terjadi melalui komunikasi nor verbal. ${ }^{18}$ Bagi Pontoh komunikasi non verbal adalah komunikasi yang menggunakan gerak, intonasi suara, simbol dan objek tambahan. ${ }^{19}$ Demikian pula Siswanto menjelaskan bahwa komunikasi non verbal juga dilakukan melalui gambar dan penggunaan arsitektur sebuah bangunan. ${ }^{20}$ Mencermati tulisan bahasa Ibrani yang digunakan oleh orang Yahudi, tulisan tersebut identik dengan simbol. Tampaknya proses pembelajaran yang dilakukan secara verbal dikuatkan lagi dengan media pendukung seperti simbol yang dipasang pada tiang pintu rumah dan pintu gerbang. Proses pembelajaran yang menggunakan media gambar, simbol, dan tulisan, menurut Nurseto dapat menjadikan informasi yang disajikan menjadi lebih konkret. ${ }^{21}$ Dengan demikian proses pembelajaran yang dilakukan oleh orang Yahudi berdasarkan Ulangan 6:6-9 tidak terhenti pada menjadikan anak-anaknya mengingat sesuatu secara abstrak tetapi dalam gambaran yang lebih konkrit. Pemasangan tanda pada tangan dan dahi dapat dilihat sebagai sebuah usaha agar anak-anak selalu mengingat perintah Tuhan dan menyadari tanggungjawab tersebut di mana saja serta melakukannya dengan penuh hormat pada Tuhan.

\section{Kesimpulan}

Pembelajaran memorisasi berdasarkan Ulangan 6:6-9 dilakukan dengan melakukan pengulangan. Proses pengulangan tersebut menghasilkan informasi yang direkam dan disimpan jumlahnya cukup banyak. Seringnya informasi yang sama disampaikan secara terus menerus dalam berbagai situasi dapat membuat anak-anak lebih mengingat informasi tersebut dan memahaminya dengan baik. Pembelajaran memorisasi dilaksanakan dengan menggunakan komunikasi verbal, hal tersebut tampak dari tindakan membicarakannya secara terus menerus. Kemudian untuk menolong anakanak memahami informasi lebih konkrit maka dilakukan dengan komunikasi non verbal menggunakan simbol, gambar, tulisan yang dipahami. Pembelajaran memorisasi tidak hanya dilakukan untuk membuat anak-anak mengingat informasi dalam jangka panjang tetapi memahaminya juga.

\section{Rekomendasi}

Dari proses penelitian yang telah dilakukan, penulis merasa bahwa kegiatan pembelajaran dalam Ulangan 6:6-9 kemungkinan berkaitan dengan pembelajaran dengan mnemonik. Oleh sebab itu, untuk penelitian lanjutan Ulangan 6:6-9 dapat juga

\footnotetext{
${ }^{18}$ Teguh Ibrahim et al., "Profil Karakter Guru Pembelajar: Sebuah Kerangka Konseptual," NATURALISTIC: Jurnal Kajian Penelitian Pendidikan dan Pembelajaran 2, no. 1 (October 2017): 8-22.

${ }^{19}$ Widya P. Pontoh, "Peranan Komunikasi Interpersonal Guru Dalam Meningkatkan Pengetahuan Anak," JURNAL ACTA DIURNA 2, no. 1 (2013): 1-11.

${ }^{20}$ Arif Siswanto, "Analisis Visual Identitas Kota Malang Melalui Foto-Foto Pada Festival Malang Tempoe Doeloe 2014: Satoes Akoe 100 Lakoe," Commonline Departemen Komunikasi 4, no. 1 (2014): 26-37.

${ }^{21}$ Tejo Nurseto, "Membuat Media Pembelajaran yang Menarik," Jurnal Ekonomi dan Pendidikan 8, no. 1 (2011): 19-35.
} 
diteliti untuk melihat kaitannya dengan mnemonik sehingga dapat berkontribusi bagi pengembangan ilmu pembelajaran terutama untuk pendidikan Kristen.

\section{Referensi}

Alkitab. Jakarta: Lembaga Alkitab Indonesia, 2011.

Anderson, Lorin W., and David R. Krathwohl. Kerangka Landasan Untuk Pembelajaran, Pengajaran Dan Asesmen: Revisi Taksonomi Pendidikan Bloom. Yogyakarta: Pustaka Pelajar, 2010.

Arianto, Arianto. "Model Pembelajaran Terpadu Untuk Meningkatkan Keterampilan Menyimak Dan Berbicara.” Al-Izzah: Jurnal Hasil-Hasil Penelitian 13, no. 1 (May 2018): 48-62.

Calvin, John. "Deuteronomy 6 Commentary - John Calvin's Commentaries on the Bible." StudyLight.org.

Darmawan, I. Putu Ayub, and Edy Sujoko. "Revisi Taksonomi Pembelajaran Benyamin S. Bloom.” Satya Widya 29, no. 1 (June 2013): 30-39.

Henry, Matthew. "Deuteronomy 6 Commentary - Matthew Henry's Complete Commentary on the Bible." StudyLight.org.

Heryanto, Heryanto. "Signifikansi Nilai Budaya Kristen Dalam Kepemimpinan Guru di Lingkungan Sekolah Kristen.” GENERASI KAMPUS 11, no. 1 (November 2018).

Ibrahim, Teguh, Dharma Kesuma, Babang Robandi, and Arie Rakhmat Riyadi. "Profil Karakter Guru Pembelajar: Sebuah Kerangka Konseptual.” NATURALISTIC: Jurnal Kajian Penelitian Pendidikan dan Pembelajaran 2, no. 1 (October 2017): 8-22.

Krathwohl, David R. “A Revision of Bloom's Taxonomy: An Overview.” Theory Into Practice 41, no. 4 (November 2002): 212-218.

Maria Lidya Wenas, and I Putu Ayub Darmawan. "Signifikansi Pendidikan Anak Dalam Perspektif Alkitab.” Evangelikal: Jurnal Teologi Injili dan Pembinaan Warga Jemaat 1, no. 2 (2017). http://journal.sttsimpson.ac.id/index.php/EJTI.

Nurseto, Tejo. "Membuat Media Pembelajaran yang Menarik." Jurnal Ekonomi dan Pendidikan 8, no. 1 (2011): 19-35.

Pfeiffer, Charles F., and Everett F. Harrison. Tafsiran Alkitab Wycliffe Vol. 1. Malang: Gandum Mas, 1962.

Pontoh, Widya P. "Peranan Komunikasi Interpersonal Guru Dalam Meningkatkan Pengetahuan Anak.” JURNAL ACTA DIURNA 2, no. 1 (2013): 1-11.

Rantesalu, Syani Bombongan. "Kompetensi Pedagogik Menurut Analisis Ulangan 6:7-9 dengan Pendekatan Hermeneutik Schleiermacher." BIA': Jurnal Teologi dan Pendidikan Kristen Kontekstual 1, no. 2 (December 2018): 153-163.

Siswanto, Arif. "Analisis Visual Identitas Kota Malang Melalui Foto-Foto Pada Festival Malang Tempoe Doeloe 2014: Satoes Akoe 100 Lakoe." Commonline Departemen Komunikasi 4, no. 1 (2014): 26-37.

Spurgeon, C. “Deuteronomy 6 Commentary - Spurgeon's Verse Expositions of the Bible." StudyLight.org.

Tety, Tety, and Soeparwata Wiraatmadja. "Prinsip-Prinsip Filsafat Pendidikan Kristen." Evangelikal: Jurnal Teologi Injili dan Pembinaan Warga Jemaat 1, no. 1 (January 2017): 55-60.

Windariyah, Devi Suci. "Kebertahanan Metode Hafalan Dalam Pembelajaran Bahasa Arab.” TA 'LIM : Jurnal Studi Pendidikan Islam 1, no. 2 (July 2018): 89-104. 